Utah State University

DigitalCommons@USU

$5-1973$

\title{
Field Measurements of Photosynthesis and Leaf Growth Rates of Three Alpine Plant Species
}

Douglas A. Johnson

Utah State University

Follow this and additional works at: https://digitalcommons.usu.edu/etd

Part of the Ecology and Evolutionary Biology Commons, Environmental Sciences Commons, and the Plant Sciences Commons

\section{Recommended Citation}

Johnson, Douglas A., "Field Measurements of Photosynthesis and Leaf Growth Rates of Three Alpine Plant Species" (1973). All Graduate Theses and Dissertations. 6269.

https://digitalcommons.usu.edu/etd/6269

This Thesis is brought to you for free and open access by the Graduate Studies at DigitalCommons@USU. It has been accepted for inclusion in All Graduate Theses and Dissertations by an authorized administrator of DigitalCommons@USU. For more information, please contact digitalcommons@usu.edu.

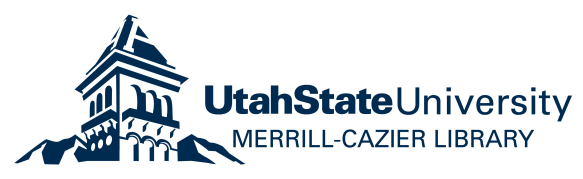




\section{FIELD MEASUREMENTS OF PHOTOSYNTHES IS AND LEAF GROWTH RATES OF THREE ALPINE PLANT SPECIES \\ by \\ Douglas A. Johnson}

A thesis submitted in partial fulfillment of the requirements for the degree

of

MASTER OF SCIENCE

in

Range Science

(Plant Ecology)

Approved:

UTAH STATE UNIVERS ITY

Logan, Utah

1973 


\section{ACKNOWLEDGEMENTS}

Grateful acknowledgement is made to Dr. Martyn M. Caldwell for his generous support in terms of time, ideas, and the preparation of this thesis. Appreciation is also extended to Drs. Herman Wiebe and Donald Sisson for their assistance in providing valuable suggestions pertaining to the fieldwork for this thesis. The assistance of Kathryn Johnson, Russell Moore, James Ehleringer, Dennis Ballinger, Rita Belserene, as well as the station support of the Institute of Arctic and Alpine Research, University of Colorado is sincerely appreciated. This study was supported by the U.S. National Science Foundation as part of the U. S. Tundra Biome of the International Biological Program. 
TABLE OF CONTENTS

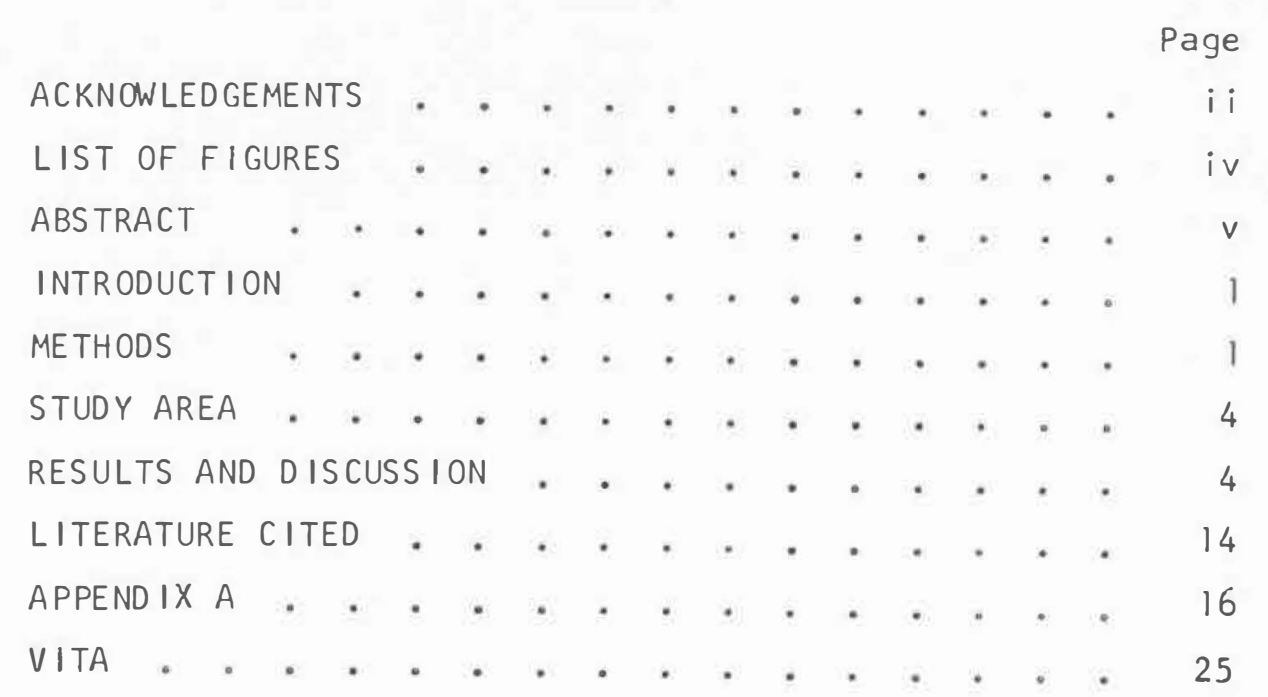




\section{LIST OF FIGURES}

Figure

Page

1. Leaf photosynthes is rates and leaf RGR of Geum rossii in the Kobresia site and the Deschampsia site. Each point on the photosynthesis figure is the mean of four to eight replicates with the vertical bars representing + one standard error. Each point on the leaf RGR $\bar{f}$ igure is the mean of ten plants with the standard errors ranging from 0.01 to 0.58. Negative leaf RGR denotes leaf senescence

2. Leaf photosynthesis rates and leaf RGR of Kobresia myosuroides in the Kobresia site and Deschampsia caespitosa in the Deschampsia site. Each point on the photosynthesis figure is the mean of four to eight replicates with the vertical bars representing \pm one standard error. Each point on the leaf RGR figure is the mean of ten plants with the standard errors ranging from 0.01 to 0.94 . Negative leaf RGR denotes leaf senescence.

3. Relative photosynthetic contributions of Deschampsia caespitosa, Geum rossi $i$, and Kobresia myosuroides at different leaf positions at three dates during the growing season. Each leaf position represents 


\section{ABSTRACT}

Field Measurements of Photosynthes is and Leaf Growth Rates of Three Alpine Plant Species

by

Douglas A. Johnson, Master of Science Utah State University, 1973

Major Professor: Martyn M. Caldwell

Department: Range Science

Leaf photosynthetic measurements using a portable ${ }^{14} \mathrm{CO}_{2}$ field system were carried out and correlative leaf relative growth rates, RGR, were determined at different leaf positions of three alpine plant species throughout the growing season. Initially there was a period of high leaf RGR associated with a period of increasing photosynthetic activity. Following this stage was a long period of no net change in length of the living leaf. During this period, photosynthetic activity generally increased to a maximum level and then decreased steadily. The final ontogenetic stage was a period of negative leaf RGR denoting leaf senescence which was associated with a marked decline in leaf $\mathrm{CO}_{2}$ uptake. Ontogenetic timing of these alpine species is geared with the surge and decline of individual leaf photosynthetic activity so that one to several leaves operating at near maximal photosynthetic capacity are always maintained during the growing season for each plant. These findings are discussed in relation to their adaptive significance for these species.

(30 pages) 


\section{INTRODUCTION}

Photosynthesis of individual leaves exhibits an increase after leaf emergence, a leveling off before or after full leaf expansion, and a decline with leaf senescence. This pattern has become apparent from field $\mathrm{CO}_{2}$ uptake studies done for individual leaves of agricultural species (e.g., Beuerlein and Pendleton, 1971; Turner and Incoll, 1971). In alpine areas where the growing season is short and relatively severe field photosynthesis measurements of whole plants have been carried out (e.g., Scott and Billings, 1964; Moser, 1973). However, little or no field work has been done in alpine areas with photosynthes is of individual leaves. The present investigation with three major alpine tundra species was concerned with investigating the field photosynthetic response of individual leaves at several leaf positions and correlating this photosynthetic response with the seasonal progressions of leaf growth rate during the alpine growing season.

METHODS

Leaf photosynthetic measurements were determined using a portable ${ }^{14} \mathrm{CO}_{2}$ field system. The field system and procedure have been described in detail by Tieszen, et al. (in press). The field system consists of a plexiglass leaf chamber which is temperature controlled by a Peltier thermoelectric stage. The procedure involves exposing an intact leaf to a ${ }^{14} \mathrm{CO}_{2}$ air mixture, immediately cooling the leaf sample in the field following exposure, subsequent drying of the exposed leaf sample, combusting this sample, and radioactivity counting using liquid scintillation techniques. 
According to studies by Ludwig and Canvin (1971) net ${ }^{14} \mathrm{CO}_{2}$ uptake in a leaf is maximum at exposure periods less than $30 \mathrm{sec}$. This initial period approximates what might be termed as gross $\mathrm{CO}_{2}$ influx. After $30 \mathrm{sec}$, net $\mathrm{CO}_{2}$ uptake decreases as the exposure time in ${ }^{14} \mathrm{CO}_{2}$ is extended and after $10 \mathrm{~min}$ approaches normal net $\mathrm{CO}_{2}$ exchange rates. This decrease in ${ }^{14} \mathrm{CO}_{2}$ uptake is associated with ${ }^{14} \mathrm{CO}_{2}$ evolution from the leaf. Thus, with exposure times of 1 min used in this study, $\mathrm{CO}_{2}$ uptake measured was between gross $\mathrm{CO}_{2}$ uptake and net photosynthes is.

All $\mathrm{CO}_{2}$ uptake determinations were carried out under a constant chamber temperature of $10.0 \pm .5^{\circ} \mathrm{C}$ which is representative of the mean daytime growing season temperatures at the study area. These were measured using a shielded copper-constantan fine wire thermocouple. Leaf temperatures were also monitored and were always within $\pm 1.0^{\circ} \mathrm{C}$ of chamber air temperature. Artificial irradiation was provided by a high intensity incandescent lamp and was monitored with a Lambda Co. Model Ll-190SR quantum sensor. A constant intensity of $2700 \pm 200$ microeinsteins $\cdot \mathrm{m}^{-2} \cdot \mathrm{sec}^{-1}$ in the $400-700 \mathrm{~nm}$ wavelength range was used for all determinations and is approximately equal to maximum midday solar radiation values. A period of five minutes was allowed for the leaf to attain a steady state gas exchange rate under these environmental conditions before ${ }^{14} \mathrm{CO}_{2}$ exposure. These temperature and radiation conditions were used consistently in this study in order to assess the combined influence of other factors such as leaf age and leaf position.

Leaf areas for Deschampsia caespitosa and Kobresia myosuroides were determined by direct measurement of leaf length and width and 
are accurate to $\pm 5 \%$. Area values for the highly dissected leaves of Geum rossii were estimated from regression relationships of leaf dry weight, leaf length and width, and leaf area which was determined by a modified optical planimeter (Caldwell and Moore, 1971). These basic relationships were determined at three times during the season.

For the leaf growth rate study, ten plants each of Geum rossii and Kobresia myosuroides in the Kobresia meadow site and ten plants each of Deschampsia caespitosa and Geum rossii in the Deschampsia meadow site were selected on 15 June. These individual plants were observed and measured every five days for leaf emergence, leaf elongation, and senescence throughout the course of the growing season. Leaf length was measured from the base of the plant to the most distal green portion of the outstretched leaf. Each leaf was individually measured and the same leaf was followed through emergence, expansion, and senescence.

From these individual leaf measurements, the mean leaf relative growth rate, RGR, was calculated by (Květ, et al., 1971):

$$
R G R=\left(\ln 1_{2}-\ln 1_{1}\right) /\left(t_{2}-t_{1}\right) \text { length } \cdot \text { length }{ }^{-1} \cdot t_{i m e^{-1}}
$$

where $\mathrm{I}_{2}$ and $\mathrm{l}_{1}$ are the lengths at times $t_{2}$ and $t_{1}$ respectively. In both the leaf photosynthetic and leaf RGR studies the same numerical identification of leaf position was used. The first green leaf present on the plant and thus the oldest living leaf on the plant was given the designation of \#l leaf, followed by the second green leaf to emerge as \#2 leaf, with successive numbering up to the youngest leaf. 
STUDY AREA

The area of the study was on Niwot Ridge ( $40^{\circ} 04^{\prime} \mathrm{N}, 105^{\circ} 36^{\prime} \mathrm{N}$ ) at an elevation of $3476 \mathrm{~m}$ in the Front Range of the Colorado Rocky Mountains. The study sites were the U. S. Tundra Biome intensive sites, one a Kobresia community and the other a Deschampsia meadow. The Kobresia site has a southwest aspect and $5^{\circ}$ slope, while the Deschampsia site has a southeast aspect and a $4^{\circ}$ slope.

The two intensive study sites are located on a gently sloping saddle and have vegetation characterized by low perennial grasses, sedges, and herbs. The Kobresia site is a well-developed mesic meadow, whereas the Deschampsia site is an area with heavy snow melt water runoff. A further characterization of the study sites can be found in Fareed (1973). Plant nomenclature follows that of Weber (1967). The $\mathrm{CO}_{2}$ uptake and leaf growth rate studies were initiated in June and continued through August, 1972.

\section{RESULTS AND DISCUSSION}

Figures 1 and 2 illustrate the photosynthetic capacity and leaf RGR of Geum rossii, Deschampsia caespitosa, and Kobresia myosuroides at different leaf positions throughout the growing season. In Geum rossii all leaves arose from the current year's growth. The first leaf in Deschampsia caespitosa and Kobresia myosuroides was one which typically had initiated growth in the prior season, but which had not attained complete exsertion and development. Thus, during the second season of growth, leaf elongation ensued.

In all species studied, the greatest leaf RGR was exhibited by 


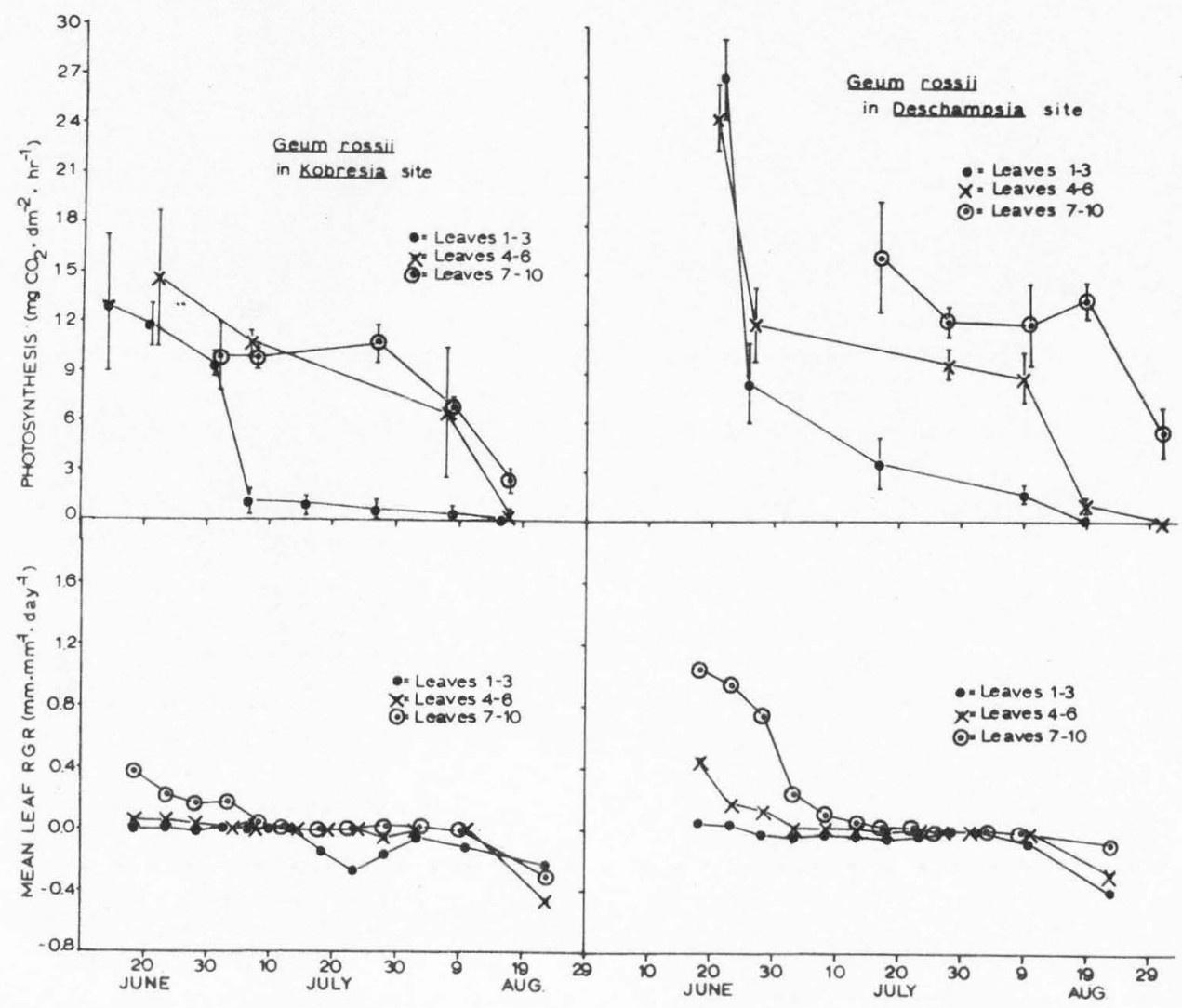

Figure 1. Leaf photosynthesis rates and leaf RGR of Geum rossii in the Kobresia site and the Deschampsia site. Each point on the photosynthesis figure is the mean of four to eight replicates with the vertical bars representing \pm one standard error. Each point on the leaf RGR figure is the mean of ten plants with the standard errors ranging from 0.01 to 0.58 . Negative leaf RGR denotes leaf senescence. 


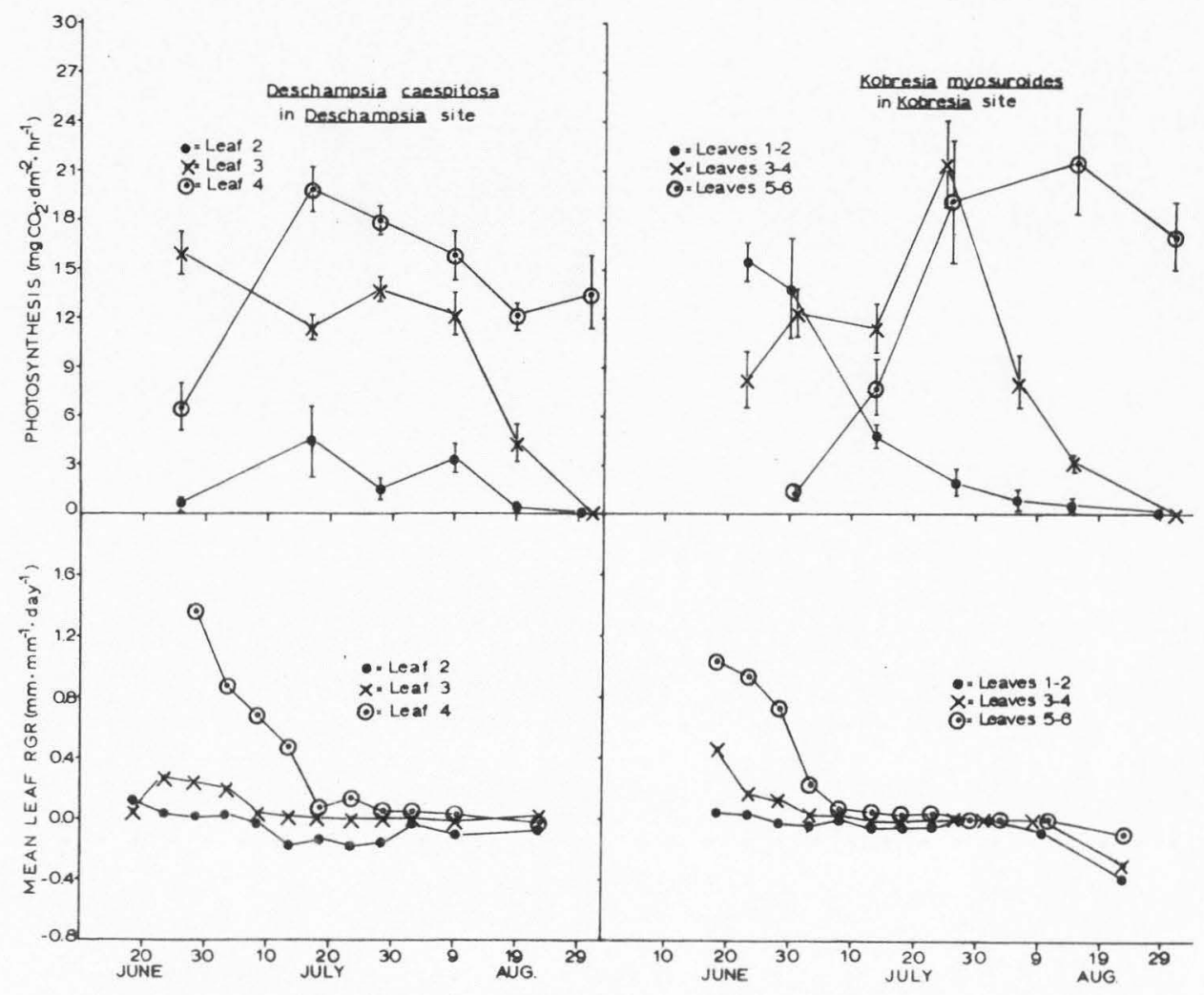

Figure 2. Leaf photosynthesis rates and leaf RGR of Kobresia myosuroides in the Kobresia site and Deschampsia caespitosa in the Deschampsia site. Each point on the photosynthesis figure is the mean of four to eight replicates with the vertical bars representing + one standard error. Each point on the leaf RGR figure is the mean of ten plants with the standard errors ranging from 0.01 to 0.94 . Negative leaf RGR denotes leaf senescence. 
the upper leaves. Presumably, leaves at lower positions on the plant exhibited the same pattern of growth but this took place prior to our first sampling date. In Deschampsia caespitosa and Kobresia myosuroides, this period of rapid growth may have taken place the previous growing season and the leaves may have been completing exsertion in this subsequent growing season. Standard errors of the leaf RGR means ranged from 0.01 to 0.94 .

A similar ontogenetic pattern was exhibited in all species studied. Initially there was a period of high leaf RGR associated with a period of increasing photosynthetic activity. Following this stage was a long period of no net change in length of the living leaf. During this period, photosynthetic activity generally increased to a maximum level and then decreased steadily. The final leaf ontogenetic stage was a period of negative leaf RGR denoting leaf senescence which was associated with a marked decline in leaf $\mathrm{CO}_{2}$ uptake rate. All species studied exhibited a decrease in photosynthetic rate prior to negative leaf RGR.

Growth in the Deschampsia meadow site was initiated during the beginning of June. Growth in the Kobresia stand site was initiated somewhat earlier in the season with substantial growth before the first sampling period. This earlier growth initiation in the Kobresia site may be attributed to the snow melt date of 22 May as compared with 9 June as the snow melt date in the Deschampsia site (Diane Ebert May, unpublished data).

This difference between sites is particularly apparent when photosynthetic and leaf relative growth rates in leaf positions \#7-10 
of Geum rossii are compared. In the Kobresia site leaves in these positions approached zero net leaf RGR near 8 July as contrasted to 18 July in the Deschampsia site. In the Kobresia site, Geum rossii leaves in positions \#7-10 declined earlier in their photosynthetic rates and exhibited less than $3 \mathrm{mg} \mathrm{CO} 2 \cdot \mathrm{dm}^{-2} \cdot \mathrm{hr}^{-1}$ uptake by 17 August. In the Deschampsia site comparable leaves exhibited rates of more than $13 \mathrm{mg} \mathrm{CO} 2 \cdot \mathrm{dm}^{-2} \cdot \mathrm{hr}^{-1}$ on 19 August. Even by 31 August these leaves had not declined to the low levels of $\mathrm{CO}_{2}$ uptake exhibited by 17 August in the Kobresia site.

This earlier decline in leaf photosynthetic capacity and leaf RGR of Geum rossii in the Kobresia site may be due to differences in plant age. The same ontogenetic sequence took place in Geum rossii in both the Kobresia and Deschampsia sites. However, due to the earlier snow melt date in the Kobresia site, the ontogeny in the Kobresia site was initiated earlier than in the Deschampsia site. Thus, as Geum rossii was completing its ontogenetic pattern in the Kobresia site, Geum rossii in the Deschampsia site was exhibiting a time lag of more than ten days.

Differences in water stress may also account for this earlier decline in the Kobresia site. Leaf water potentials for Geum rossii as measured by the scholander pressure bomb technique were on the order of -18 bars by 18 July in the Kobresia site, whereas comparable leaf water potentials were not observed until 29 July in the Deschampsia site. Leaf water potential measurements throughout the 1972 growing season ranged from - 1 bar to less than -30 bars in Deschampsia caespitosa, -1 bar to -20 bars in Geum rossii, and -7 bars to -29 bars in Kobresia myosuroides. Leaf photosynthet ic 
capacities of Geum rossi i and Deschampsia caespitosa have been shown to be significantly depressed with these decreases in leaf water potential for leaves of the same age (Johnson, et al., in press). In addition the number of leaves operating at near maximal efficiencies at any specific time may also be reduced.

Leaves in the lower positions exhibited their highest photosynthetic capacity in the early portion of the season and generally showed a steady decline throughout the rest of the season. However, as photosynthetic activity in the older senescing leaves declined, new leaves were emerging to assume the function of the primary photosynthetic structures (Fig. 3). Ontogenetic timing of these alpine species is geared with the surge and decline of individual leaf photosynthetic capacity so that one to several leaves operating at near maximal photosynthetic capacity are always maintained during the growing season of each plant. This generalized seasonal $\mathrm{CO}_{2}$ uptake pattern has been shown for other species such as Nicotiana sanderae (Šesták and Čatský, 1962) and Sorghum almum and vigna luteola (Ludlow and Wilson, 1971).

When leaves are first formed, they are developed near the top of the canopy and are well illuminated. As new leaves are produced these older leaves become increasingly shaded. Thus, the effects of leaf age on photosynthetic capacity are confounded with the effects of decreased light intensity. Osman and Milthorpe (1971) and Woledge (1971) indicate that there is a more marked decline in photosynthetic capacity with age under high radiation intensities than under low light conditions. Furthermore, Woledge (1971) indicated that the old leaves become saturated at low light intensities, whereas saturation 

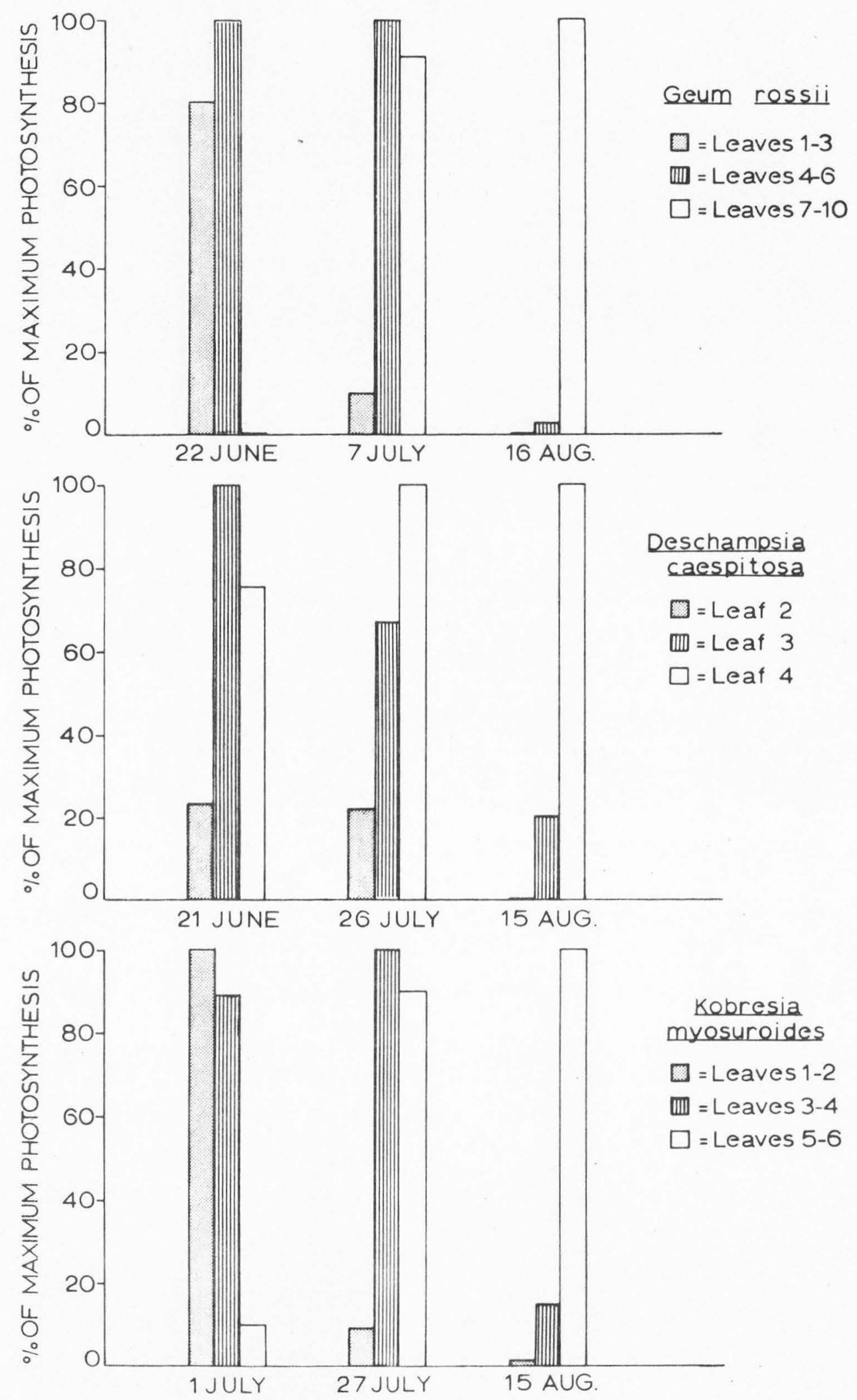
in the young leaves is not reached until higher light intensities. Thus, under high light intensities the $\mathrm{CO}_{2}$ uptake activity is substantially higher in the younger leaves than in the older leaves.

Having the older leaves in the position of low light intensity may both prolong the photosynthetic contribution of the older leaves and minimize the reduction in photosynthesis due to the aging of leaves. With this strategy the leaves of the plant are arranged for maximum photosynthesis at any one time of the season. The young leaves with their peak photosynthetic capacities intercept the high light intensities, whereas the older leaves with their declining stages of photosynthes is receive lower light intensities. This results in maximum photosynthetic efficiency in the upper, younger leaves as well as prolonged photosynthetic efficiency in the lower, older leaves. Since these older leaves are saturated at low light intensities, shading would be of no immediate disadvantage for these older leaves.

When the photosynthetic capacity of these older leaves reaches extremely low levels, death of these leaves would represent a conservation of energy and nutrients for the plant (Leopold, 1961; Hopkinson, 1966; Leopold, 1967). Williams (1955) indicates that this decline and eventual senescence of the older leaves permits a reutilization of nutrients from these organs. Williams (1936) showed that there was a net loss of nitrogen and phosphorus from the older leaves into the upper, younger leaves. According to Hopkinson (1966) these leaf nutrients in the older leaves can presumably be more 
profitably used to produce photosynthetic surfaces at more favorably illuminated sites. Thus, this redistribution of nitrients results in the continuous rearrangement of the assimilating surfaces as tc ensure the most efficient exploitation of the available light energy. When a leaf's photosynthetic contribution is no longer worth the price of its maintenance, the plant mobilizes as much useful material as possible before total leaf death takes place.

This change in leaf photosynthetic capacity with leaf age was also apparent in multiple regression analys is of the leaf photosynthesis data. A leaf phenology index was a consistently significant independent variable and corresponded to the periods of positive leaf RGR, zero leaf RGR, and negative leaf RGR. In addition the leaf area/dry weight ratio was a consistently significant independent variable. A reciprocal function, specific leaf weight (SLW, dry weight/area), has been used as an indicator of internal leaf anatomy in crop species (e.g., Pearce, et al., 1969; Wolf and Blaser, 1972). Straley and Cooper (1972) propose that light intensity during and following leaf formation as well as light intensity within the canopy are principal factors influencing SLW for leaves. Thus, it was not surprising that both the leaf phenology index and the leaf area/dry weight ratio were consistently significant, since both these variables represent to some degree the internal metabolic activity of the leaf. 


\section{LITERATURE CITED}

Beuerlein, J.E. and J.W. Pendleton. 1971. Photosynthetic rates and 1 ight saturation curves of individual soybean leaves under field conditions. Crop Sci. 11:217-219.

Caldwel1, M. M. and R. T. Moore. 1971. A portable small-stage photoelectric planimeter for leaf area measurements. J. Range Manage. 24:394-395.

Fareed, M. 1973. Canopy structure and phenology of alpine tundra vegetation. M. S. Thesis, Utah State University, Logan, Utah. $43 \mathrm{pp}$.

Hopkinson, J.M. 1966. Studies on the expansion of the leaf surface. VI. Senescence and the usefulness of old leaves. J. Exp. Bot. $17: 762-770$.

Johnson, D. A., M. M. Caldwell, and L. L. Tieszen. (In press). Photosynthesis in relation to leaf water potential in three alpine plant species. Proc. IBP Tundra Biome Primary Production Meeting, Dublin, Ireland, March 31-April 3, 1973.

Květ, J., J.P. Ondok, J. Nečas, and P. G. Jarvis. 1971. Methods of growth analysis. In Šestak, Z., J. Čatský, and P. G. Jarvis (eds.), Plant Photosynthetic Production Manual of Methods. Dr. W. Junk N. V. Publishers, The Hague, 343-384.

Leopold, A. C. 1961. Senescence in plant development. Science 134:1727-1732.

Leopold, A. C. 1967. Developmental aspects of plant senescence. Proc. 17th Int. Hort. Congress 3:285-290.

Ludlow, M. M. and G. L. Wilson. 1971. Photosynthes is of tropical pasture plants. III. Leaf age. Austr. J. Biol. Sci. 24:1077-1088.

Ludwig, L. J. and D. T. Canvin. 1971. An open gas-exchange system for the simultaneous measurement of the $\mathrm{CO}_{2}$ and ${ }^{4} \mathrm{CO}_{2}$ fluxes
from leaves. Can. J. Bot. 49:1299-1313.

Moser, V. W. 1973. Licht, Temperatur und Photosynthese an der Station "Hoher Nebelkogel" (3184 m). In Ellenberg, H. (ed.), Ökosystemforschung. Springer-Verlag, Heidelberg, 203-223.

0sman, A. M. and F. L. Milthorp. 1971. Photosynthes is of wheat leaves in relation to age, illuminance, and nutrient supply. 11. Results. Photosynthetica 5:61-70.

Pearce, R. B., G. E. Carlson, D. R. Barnes, R. H. Hart, and C. H. Hanson. 1969. Specific leaf weight and photosynthes is in alfalfa. Crop Sci. 9:423-426. 
Scott, D. and W. D. Billings. 1964. Effects of environmental factors on standing crop and productivity of an alpine tundra. Ecol. Monogr. 34:243-270.

Šesták, Z. and J. Catský. 1962. Intensity of photosynthes is and chlorophyll content as related to leaf age in Nicotiana. Biologica Pl. 4:131-140.

Straley, C. S. and C. S. Cooper. 1972. Effect of shading mature leaves of alfalfa and sainfoin plants on specific leaf weight of leaves formed in sunlight. Crop Sci. 12:703-704.

Tieszen, L. L., D. A. Johnson, and M. M. Caldwell. (In press). A portable system for the measurement of photosynthes is using 14-carbon dioxide. Photosynthetica.

Turner, N. C. and L. D. Incoll. 1971. The vertical distribution of photosynthesis in crops of tobacco and sorghum.

J. Appl. Ecol. 8:581-591.

Weber, W. A. 1967. Rocky Mountain Flora. Univ. Colorado Press, Boulder, Colorado. 437 pp.

Williams, R. F. 1936. Physiological ontogeny in plants and its relation to nutrition. Austr. J. Exp. Biol. Med. Sci. $14: 165-185$.

Williams, R. F. 1955. Redistribution of mineral elements during development. Ann. Rev. Plant Physiol. 6:25-42.

Woledge, J. 1971. The effect of light intensity during growth on the subsequent rate of photosynthes is of leaves of tall fescue. Ann. Bot. 35:311-322.

Wolf, D. D. and R. E. Blaser. 1972. Growth rate and physiology of alfalfa as influenced by canopy and light. Crop Sci. $12: 23-26$. 
APPENDIX A - - A Portable System for the Measurement of Photosynthes is Using 14-Carbon Dioxide 


\section{Delivery System:}

A ir mixtures containing ${ }^{14} \mathrm{CO}_{2}$ are ordered from Matheson Gas Products and contain $300 \mathrm{ppm} \mathrm{CO}_{2}$ and a specific activity of 1.5 mcurie.mmole $e^{-1}$. With our flow rates and exposure periods, more than 400 analyses can be made from each bottle. Since absolute determinations of photosynthesis are critically dependent on accurate analyses of $\mathrm{CO}_{2}$ concentrations and ${ }^{14} \mathrm{CO}_{2}$ specific activity, a routine procedure for calibrating all air mixtures is used. The cylinders are analyzed for total $\mathrm{CO}_{2}$ concentration with a differential infrared gas analyzer, IRGA, with an accuracy of at least 1 ppm. A correction is not applied for the differential sensitivity of the infrared analyzer to ${ }^{14} \mathrm{CO}_{2}$.

The specific activity is determined by absorbing all $\mathrm{CO}_{2}$ from a known volume of air and subsequent absolute counting. Air is bubbled from the lecture bottle at a known flow rate through a series of five absorbing vessels with the intakes in each vessel immersed under $1 \mathrm{ml}$ of NCS. At the end of 30 seconds, the air flow is stopped, the NCS divided into $0.5 \mathrm{ml}$ portions, $10 \mathrm{ml}$ of counting solution added $(270 \mathrm{ml}$ methanol, $460 \mathrm{ml}$ toluene, $5 \mathrm{~g} \mathrm{PPO}$, and $100 \mathrm{mg}$ of POPOP), and the samples counted using the channels ratio method for quench correction.

\section{Leaf Chamber with Temperature Control}

Components of the temperature controlled delivery system are illustrated in Figure 1. The leaf chamber (Figure 2) is constructed of $1 / 4^{\prime \prime}$ plexiglass and consists of a hinged top and a bottom with a ${ }^{14} \mathrm{CO}_{2}$ labeled-air inlet, an unlabeled-air inlet and an air outlet. Polyurethane strips line the borders of both the top and bottom 


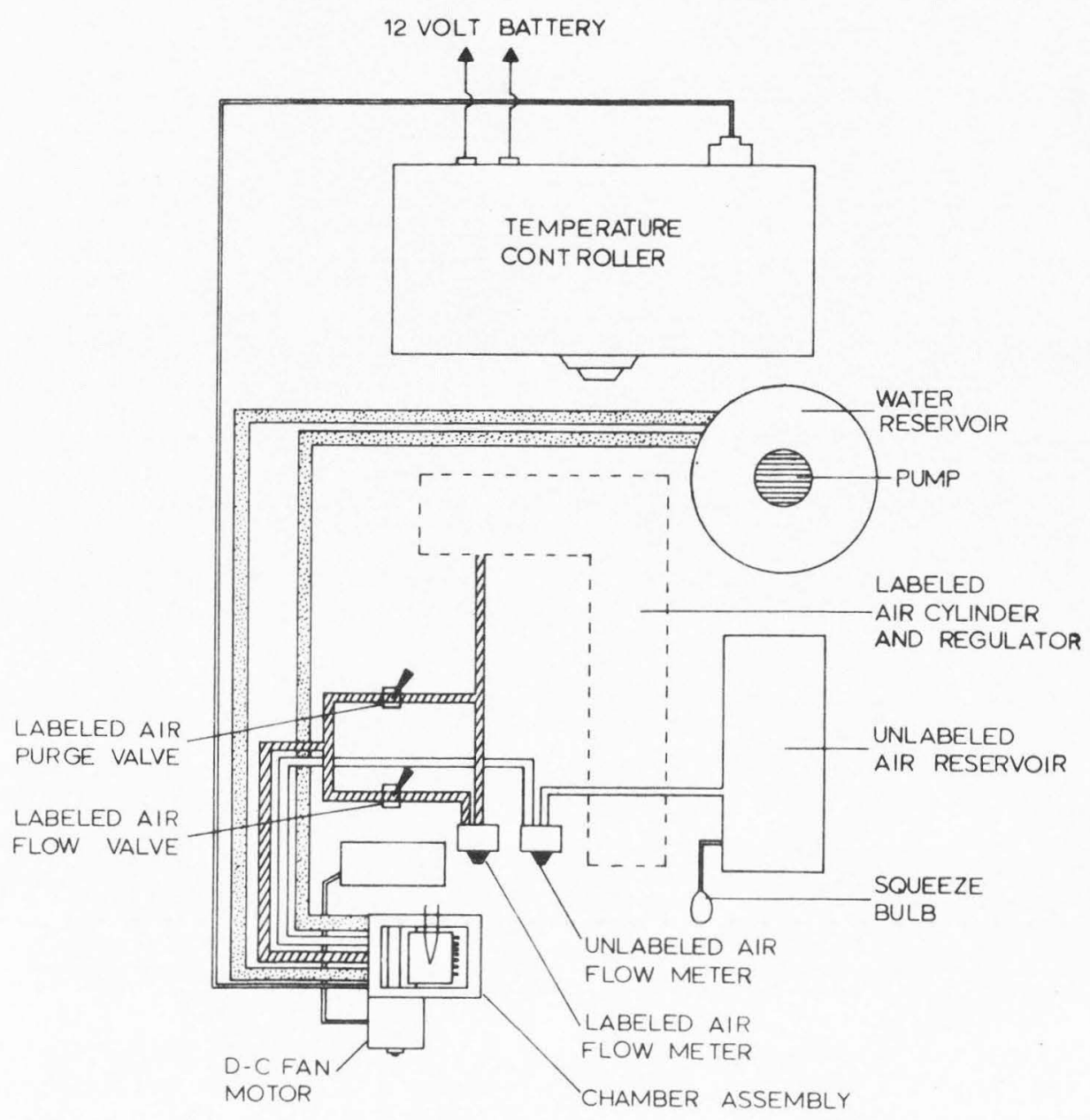

Figure 1. Schematic of system used to deliver prepared ${ }^{14} \mathrm{CO}_{2}$ air mixture to the temperature controlled leaf chamber. The Iabeled air cylinder and regulator are represented with dashed lines. Board on which system is mounted is about $74 \mathrm{~cm}$ in 1 ength and $60 \mathrm{~cm}$ in width. Total weight of the field system is about $15 \mathrm{~kg}$ without the 12 volt battery. 
TOP VIEW

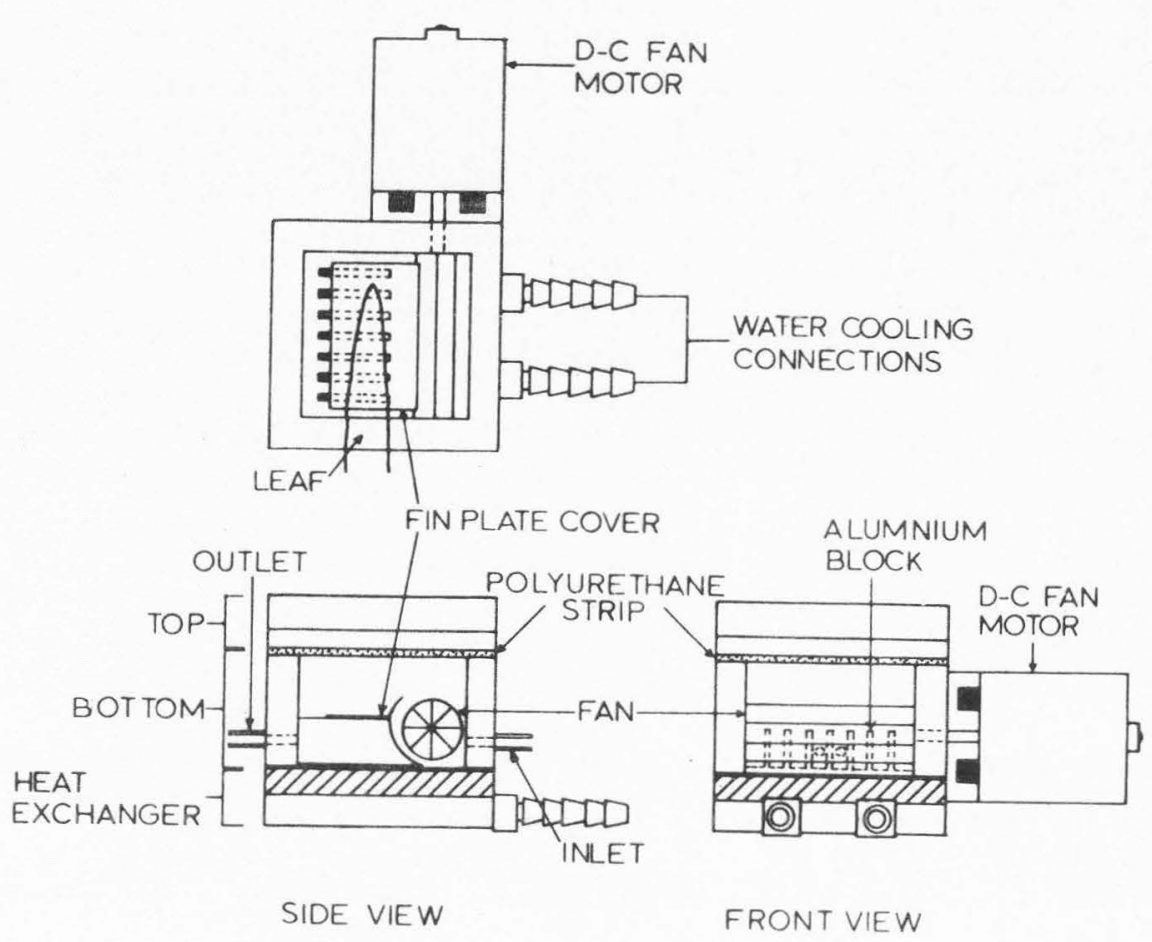

Figure 2. Diagram of temperature controlled leaf chamber showing the thermoelectric stage, mica, aluminum fins, fin cover plate, "squirrel cage" fan, and plexiglass construction. 
chambers preventing leaf damage during exposure yet providing a nearly airtight seal. This chamber is mounted on a peltier thermoelectric stage which acts as a heat exchanger for the chamber. Mounted on the thermoelectric stage is an aluminum block with fins for maximizing convective heat exchange between the thermoelectric stage and the leaf chamber. A layer of mica separates the aluminum block from the thermoelectric stage. This mica layer conducts heat effectively to the aluminum block, and electrically insulates the block from the thermoelectric stage. An aluminum cover plate is mounted across the top of the aluminum fins. A circular "squirrel cage'l fan, milled from a teflon rod and driven by a dc motor with rheostatic control, continually circulates air between the aluminum fins and then across the plant leaf. This effectively exchanges heat between the leaf and the Peltier heat exchanger, minimizes boundary layer development around the leaf, and mixes the chamber air.

The portion of the thermoelectric heat exchanger that is external to the leaf chamber must usually be cooled. This is accomplished by a water cooling system. The water cooling system has a dc operated pump which circulates water from a one gallon insulated reservoir. The reservoir is filled two-thirds full with ice and provides adequate cooling for more than eight hours of operation. The cooling reservior is 1 inked to the thermoelectric module with $1 / 8^{11} 1$. D. tygon tubing wrapped with aluminum foil. The leaf chamber and thermoelectric module are mounted on a flexible goose neck from a microphone stand. The goose neck is fitted with a stake which is pushed into the ground. This system allows for a great deal of maneuverability while at the 
same time giving a firm and steady support during the exposure period. The thermoelectric module is controlled by a bipolar proportional controller. The bipolar nature of the controller allows for both heating and cooling of the leaf chamber. The leaf chamber has a temperature control range from $0^{\circ} \mathrm{C}$ to $50^{\circ} \mathrm{C}$ and a stability of $\pm 5^{\circ} \mathrm{C}$. The controller can be operated from a 12 volt dc source, has dimensions of $20 \mathrm{~cm} \times 36 \mathrm{~cm} \times 25 \mathrm{~cm}$ and a total weight of $11.5 \mathrm{~kg}$.

Because of the relatively large chamber volume in this temperaturecontrolled leaf chamber, it was necessary to initially flush the leaf chamber rapidly with ${ }^{14} \mathrm{CO}_{2}$-labeled air. This rapid replacement of the leaf chamber air with ${ }^{14} \mathrm{CO}_{2}$-labeled air is of paramount importance if absolute values of photosynthes is are to be obtained. This is accomplished with two lever-operated toggle valves. One valve is placed immediately after the ${ }^{14} \mathrm{CO}_{2}$-labeled air flow meter and the other valve is placed in a by-pass around this flow meter. With sufficient pressure in the labeled-air line, the by-pass valve can be depressed and the leaf chamber purged with labeled air in less than three seconds.

When ambient air temperatures are not used, a period of equilibration is necessary for the leaf to attain a new steady-state temperature and photosynthetic rate. A 2-1iter rubber air reservoir with an attached "squeeze bulb" for pressurizing this reservoir provides a constant flow of unlabeled air during this equilibration time. In order to reduce $\mathrm{CO}_{2}$ diffusion the air 1 ines were constructed of $1 / 8^{\prime \prime}$ copper tubing and fittings. 


\section{Exposure of Plant:}

Use of this exposure system involves placing an intact leaf (or other plant part) across the lower portion of the chamber and tightly closing the chamber top. The unlabeled air reservoir is filled, the chamber is appropriately oriented, unlabeled air flow is initiated, the chamber fan and water pump are started, and the bipolar controller is adjusted to the desired temperature. After leaf temperature and photosynthetic equilibration, the unlabeled air stream is stopped, and the by-pass valve is opened for purging of the chamber with labeled air. Then the by-pass valve is closed and simultaneously the labeled-air flow valve is opened for the short exposure period.

\section{Sample Preparation:}

Following exposure, the labeled section is immediately cut, its area is measured, and it is placed in a vial on ice in a freezing chest until it can be returned to the laboratory for processing. The sample is then placed in a drying oven at $100^{\circ} \mathrm{C}$ for 12 hours. The dry weight of the sample is taken and it is placed in a tightly capped storage or scintillation vial until combustion.

\section{Combustion:}

A dry in-vial combustion technique provides a rapid, convenient method of combustion and allows accurate determinations of ${ }^{14} \mathrm{CO}_{2}$ from exposed leaf samples. This procedure involves making a cup container from lens paper soaked in black ink and placing it into a coiled wire holder. The cup container in the wire holder is then placed into an empty scintillation vial. A dried sample is placed into the cup 
container, the vial is momentarily flushed with a stream of pure oxygen, and the vial is immediately capped tightly with a \#15 serum stopper cap. The sample in the coiled wire stand is then ignited with a focused light beam from a modified slide projector. The sample ignites and burns to completion in approximately 5 seconds. Maximum sample size for this technique is dependent upon caloric content of the material and is usually less than $10 \mathrm{mg}$ dry weight.

\section{Counting:}

After a 5 minute cooling period, $0.5 \mathrm{ml}$ of NCS are injected through the serum stopper cap with a glass syringe. After an absorption period of 6 hours (sufficient for complete absorption), the serum stopper cap is removed and $20 \mathrm{ml}$ of scintillation grade counting solution are placed in the vial which is then closed with a cap containing a teflon liner. A combination of NCS and a toluene base scintillation liquid minimizes problems of chemiluminescence, remains stable for at least several days, and yields consistent counting efficiencies of $70-75 \%$. The samples are counted in a liquid scintillation counter. The counting efficiency for each vial is determined by the channels ratio method and DPM are calculated. The calibration curve is established with a toluene base quenched standard set.

\section{Calculations:}

The absolute rates of $\mathrm{CO}_{2}$ fixation $(P)$ are calculated from the counts per minute (CPM), counting efficiency as a fraction (E), area in $\mathrm{dm}^{2}$ or gram dry weight of the leaf sample (A), exposure time 
in minutes $(T)$, and the specific activity of the ${ }^{14} \mathrm{CO}_{2}$ air mixture $(\mathrm{SA})$. The conversion equation can be expressed as:

$$
\begin{aligned}
P & =\frac{(C P M)\left(4^{\prime}+\mathrm{mg} \cdot \mathrm{mMole}^{-1} \mathrm{CO}_{2}\right)}{(E)(T, \mathrm{~min})\left(2.22 \times 109 \mathrm{DPM} \cdot \mathrm{mc}^{-1}\right)\left(\mathrm{SA}, \mathrm{mc} \cdot \mathrm{mMole}^{-1} \mathrm{CO}_{2}\right)\left(\mathrm{A}, \mathrm{dm}^{2}\right)} \\
& =\frac{(\mathrm{CPM})\left(1.19 \times 10^{-6}\right)}{(\mathrm{E})(\mathrm{T})(\mathrm{SA})(\mathrm{A})} \mathrm{mg} \mathrm{CO} \mathrm{Cm}^{-2} \cdot \mathrm{hr}^{-1}
\end{aligned}
$$

CPM $=$ COUNTS PER MINUTE

$E=E F F I C I E N C Y$ AS A FRACTION, CPM/DPM

$T=$ EXPOSURE TIME AS PART OF A MINUTE

SA = SPECIFIC ACTIVITY OF ${ }^{14} \mathrm{CO}_{2}$-AIR MIXTURE

$A=A R E A$ OF SAMPLE

In summary, the system described is inexpensive relative to most gas analysis systems, has the advantage of ease of use and complete portability, and provides data comparable to those obtained with conventional IRGA techniques. The method is recommended whenever portability is an essential prerequisite or where IRGA methods are impractical. 


\author{
VITA \\ Douglas A. Johnson \\ Candidate for the Degree of \\ Master of Science
}

Thesis: Field Measurements of Photosynthesis and Leaf Growth Rates of Three Alpine Plant Species

Major Field: Plant Ecology

Biographical Information:

Personal Data: Born at Montevideo, Minnesota, December 6, 1949 , son of Thomas W. and Dorothy D. Johnson. Married Kathryn Ros ine January 1, 1972.

Education: Attended elementary and high school at Milan, Minnesota; graduated from Milan High School, Milan, Minnesota, in 1967. Received the Bachelor of Arts degree in Biology from Augustana College, Sioux Falls, South Dakota in 1971.

Professional Experience: 1971-1973, NDEA Fellow, Utah State University; 1970-1971, Research Ass istant, conducted ecophysiological research at Augustana College, Sioux Falls, South Dakota. 